\title{
The determinants of households' flood mitigation decisions in France - on the possibility of feedback effects from past investments
}

\author{
Claire Richert $^{1}$, Katrin Erdlenbruch ${ }^{1}$ and Charles Figuières ${ }^{2}$ \\ ${ }^{1}$ IRSTEA, UMR G-EAU, Montpellier, France \\ ${ }^{2}$ INRA, UMR LAMETA, Montpellier, France
}

September 26, 2016

\begin{abstract}
In this paper, we investigate the determinants of private flood mitigation in France. We conducted a survey among 331 inhabitants of two flood-prone areas and collected data on several topics, including individual flood mitigation, risk perception, risk experience, and sociodemographic characteristics. We estimate discrete choice models to explain either the precautionary measures taken by the household, or the intention to undertake such measures in the future. Our results confirm that the Protection Motivation Theory is a relevant framework to describe the mechanisms of private flood mitigation in France, highlighting in particular the importance of threat appraisal and previous experience of floods. Some sociodemographic features also play a significant role in explaining private flood mitigation. We also observed that respondents who had already taken precautionary measures have a lower perception of the risk of flooding than respondents who planned to implement such measures at the time of the survey. This result can be explained by the existence of a feedback effect of having taken precautionary measures on risk perception. If subsequent studies support this assumption, it would imply that intended measures, rather than implemented ones, should be examined to explore further the determinants of private flood mitigation.
\end{abstract}

JEL Classification: Q54; D81; R22

Keywords: floods; risk; mitigation; risk perception; France

\section{Introduction}

In 2014, floods accounted for more than a third of the total estimated damage caused by natural disasters worldwide, which amounted to 100 billion US dollar. ${ }^{1}$ Thus, they are already a major source of concern. In addition, the frequency and magnitude of extreme events such as floods are expected to be modified due to climate

\footnotetext{
${ }^{1}$ http : //www . emdat .be/disaster_trends/index.html
} 
change (Patwardhan et al., 2007). As a result, adaptation to natural disasters, and in particular to floods, is one of the key challenges humans will have to face to build and maintain sustainable societies. France is very affected by floods, whose annual cost is over one billion Euros (OECD, 2014), and one in four inhabitants is exposed to this risk (DGPR, 2011). ${ }^{2}$ Yet so far, very few studies have investigated flood prevention measures in France (Poussin et al., 2014, 2015).

The measures aimed at protecting people from flood risks or mitigating their negative consequences can be classified as public or private actions. Among public responses are zoning policies, solidarity and compensation schemes, and collective protection measures, like dykes or flood retention basins (Erdlenbruch et al., 2009, Picard, 2008). On the other hand, individuals themselves can take actions. In many countries, they can subscribe to private insurances aimed at compensating monetary losses after a natural disaster. In France, since there is a compulsory national compensation system (Catnat), individuals do not take the decision to buy an insurance or not, but they can decide to take precautionary measures aimed at mitigating the consequences of floods in their home, such as installing pumps or watertight doors and windows. This can be seen as an auto-insurance (Carson et al., 2013).

Several points can be raised to underline the paramount importance of private precautionary measures for the sustainability of socio-ecological systems. First, large structural flood defenses such as dams, storage reservoirs and embankments lack reversibility and can provide a misleading feeling of complete safety among populations exposed to floods (Kundzewicz, 1999). For this reason, they may hinder adaptation to changing risks of flooding. Moreover, they can harm ecosystems (Werritty, 2006). Conversely, since private precautionary measures are more local and can be designed for the specific situation and exposure of a household, they may be more flexible and have less impact on the environment than public flood defenses. Moreover, by implementing precautionary measures, individuals take responsibility for their own safety. Hence, the use of such measures can help maintain a certain awareness of the risk of flooding among exposed populations. Finally, several studies suggest that individual precautionary measures have great potential to reduce the consequences of natural disasters. For instance, Poussin et al. (2015) showed that elevating buildings could reduce the ratio of total damage to total building values by $48 \%$ in three different areas in France. Similar results have been obtained in Germany (Kreibich et al., 2005) and in the Netherlands (Botzen et al., 2009).

This paper recognizes the importance of private initiatives and investigates the mechanisms at stake when people decide whether to take precautionary measures or not. We combine economic approaches, stressing the importance of individual decision making in investing in self-insurance for their properties (Carson et al., 2013) and psychological approaches, highlighting the importance of perceptions and emotions to explain people's motivations to take actions in order to reduce their risk vulnerability (Rogers, 1975).

Several studies on individual flood preparedness have identified the Protection Mo-

\footnotetext{
${ }^{2}$ This figure was estimated by taking into account all the population living within the limits of areas potentially affected by extreme flood events (more than 100-year flood events).
} 
tivation Theory as a relevant framework to explain the implementation of precautionary measures (Grothmann and Reusswig, 2006, Poussin et al., 2014, Reynaud et al., 2013). However, in spite of the overall adequacy of this framework, and as highlighted by Bubeck et al. (2012), most studies are cross-sectional and may thus neglect possible feedback effects from already adopted precautionary measures on explanatory factors.

This article thus has two main objectives: i) to test the relevance of the Protection Motivation Theory in France, and if necessary to expand its framework by including the effects of socio-demographic variables, and ii) to investigate whether past decisions have an impact on people's perceptions and intentions, and how these feedback effects in turn affect the robustness of the Protection Motivation Theory.

To examine these questions, we conducted a survey among households in flood prone areas in the South of France, that have been hit by major floods at different points in time during the last 20 years. We collected data on exposure, attitudes, risk perception, experience of floods, characteristics of housing, and socio-demographic features from 331 households. We explored possible feedback effects by asking the respondents not only to indicate which precautionary measures they took, but also which ones they considered implementing at the time of the survey. We used discrete choice decisions models (Train, 2009) to compare the adequacy of the Protection Motivation Theory to explain implemented and planned measures and compared the perceptions and emotions of people who had already taken measures with those of respondents who still considered taking actions in the future.

In line with the existing literature, we confirm the relevance of the Protection Motivation Theory to explain private flood mitigation. Our results highlight the importance of threat appraisal, threat experience appraisal and, to a lesser extent, coping appraisal. In addition, we provide evidence for a feedback effect of the implementation of precautionary measures on risk perceptions.

In section 2, we explain the Protection Motivation Theory and its strengths and weaknesses. In section 3, we present the survey designed to investigate the drivers of private flood mitigation and the data we collected and then explain how we statistically analysed this information. We present our results in section 4 before discussing them in section 5. Finally, in section 6 we present our conclusion.

\section{Literature on Protection Motivation Theory}

The Protection Motivation Theory was first proposed by Rogers (1975) and applied in the health domain. It was further developed by Milne et al. (2000) and adapted to the context of floods by Grothmann and Reusswig (2006). According to this framework and as presented in Figure 1, the higher an individual's appraisal of the threat of flooding, the more likely he/she will respond to this risk by adopting either non protective responses, such as a fatalist position, or by taking precautionary measures. The individual's coping appraisal will influence the type of response: the more a person thinks that he/she is able to protect him/herself against the consequences of floods, the more he/she will tend to take precautionary measures 
rather than a non protective response. People who have already experienced a flood would be expected to be all the more likely to take precautionary actions that the event that affected them was severe. On the other hand, reliance on public flood protection and actual barriers, such as a lack of monetary resources, would be expected to negatively affect the implementation of precautionary measures.
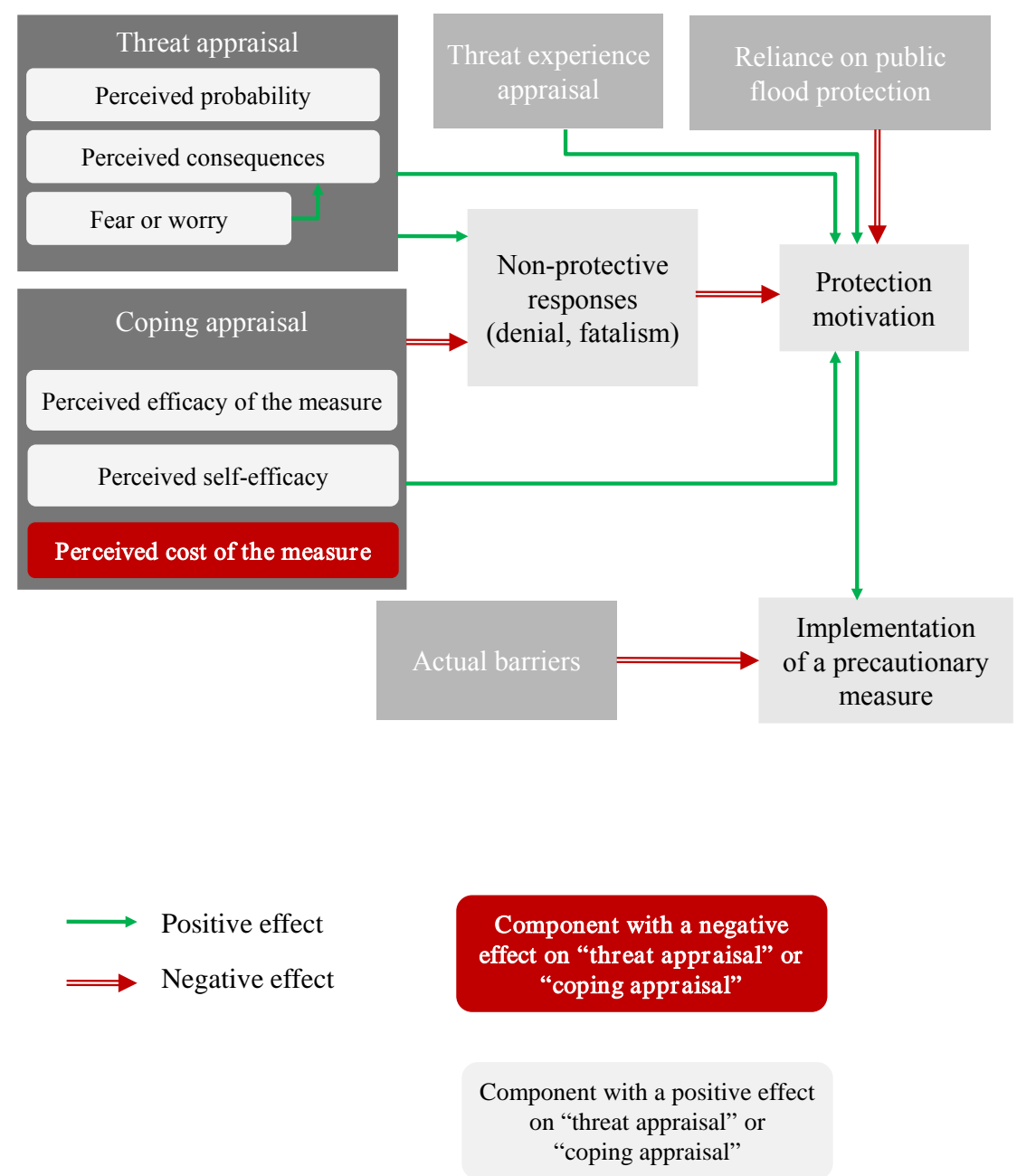

Component with a positive effect on "threat appraisal" or "coping appraisal”

Figure 1: The Protection Motivation Theory.

Source: adapted from Grothmann and Reusswig (2006)

The Protection Motivation Theory has been successfully applied to explain private flood mitigation in several countries (Glenk and Fischer, 2010, Grothmann and Reusswig, 2006, Poussin et al., 2014, Reynaud et al., 2013). Thus, it appears to be quite robust and flexible. However, since most studies are cross-sectional, they examine the links between perceptions, emotions, and flood mitigation at one point in time. As a result, they may ignore possible feedback effects from precautionary measures that have already been taken (Bubeck et al., 2012). 


\section{Method}

\subsection{Sample}

Figure 2 shows the geographical location of the two departments surveyed: the Aude department and the Var department. Both departments are subject to flash floods. The Aude department was severely impacted by such a phenomenon in November 1999. Thirty-five people died and it caused an estimated loss of 771 million euros (Vinet, 2008). The Var department was hit by a major flash flood in June 2010 that killed 26 people. The estimated damage due to this disaster was between 1,000 and 1,500 million euros (Vinet et al., 2012). The respondents were selected so that approximately $80 \%$ of the sample had already experienced at least one flood and lived in municipalities that are still exposed to the risk of flash floods. The choice of this sample ensured that the survey targeted a majority of people concerned by the risk of flooding while still making it possible to examine the effect of having experienced a flood on private mitigation.

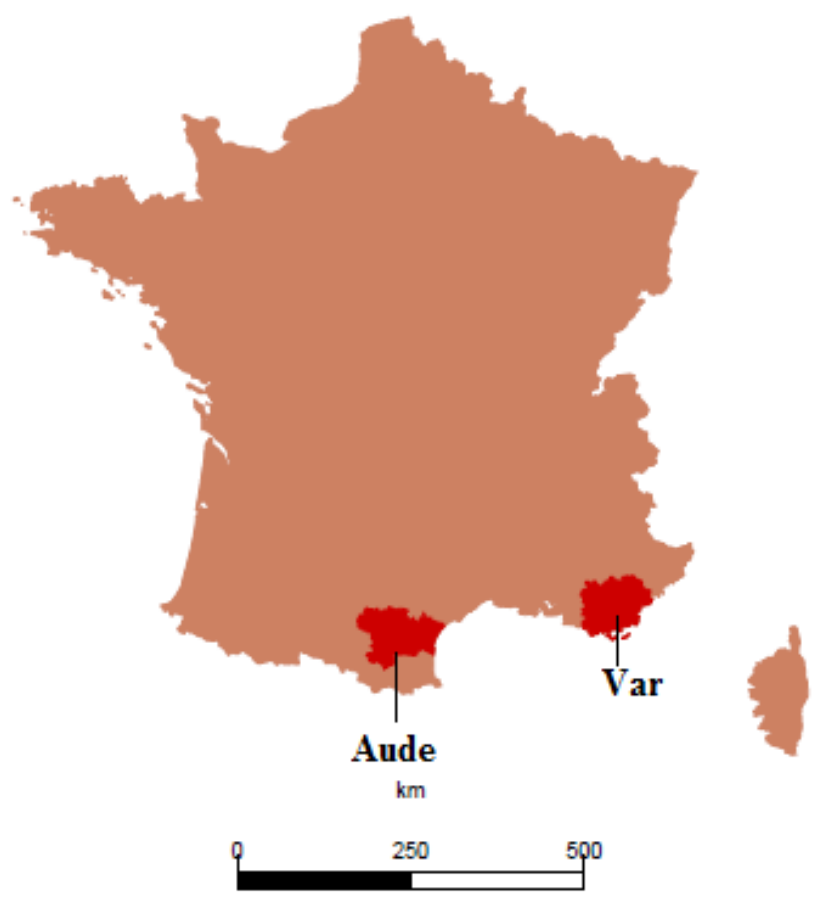

Figure 2: Geographical location of the French departments surveyed.

In total, 331 people took part in the survey in which face-to-face interviews were conducted in summer 2015. A total of 272 respondents out of 331 answered all the 
questions used in the analyses reported here. Because we wanted approximately $80 \%$ of the respondents to have experienced floods, our sample is not representative of the French population. Nevertheless, the heterogeneity of the sample is sufficient to account for the effect of sociodemographic features on private flood mitigation. Indeed, as shown in Table 1, approximately half the final sample was composed of women and half of men, and half of respondents were living in the Aude department and half in the Var at the time of the survey. Similarly, half the respondents lived in towns with more than 10,000 inhabitants and half in municipalities with less than 10,000 inhabitants. Half the sample did not have a high school diploma and two thirds owned their home. All age categories were represented. Since only $58 \%$ of the respondents gave their income, this variable was not taken into account to describe the sample or for subsequent analyses.

Table 1: Distribution of sociodemographic variables in the sample

\begin{tabular}{ccc}
\hline Variable & Category & $\begin{array}{c}\text { Sample } \\
\text { distribution }\end{array}$ \\
\hline \multirow{2}{*}{ Department } & Aude & $49.3 \%$ \\
& Var & $50.7 \%$ \\
\hline \multirow{2}{*}{ Gender } & Male & $46.7 \%$ \\
& Female & $53.3 \%$ \\
\hline \multirow{2}{*}{ Age } & $<30$ & $17.6 \%$ \\
& $30-44$ & $21.3 \%$ \\
Education level & $45-59$ & $25.0 \%$ \\
& $60-74$ & $26.5 \%$ \\
\hline \multirow{2}{*}{ Ownership of the home } & $>74$ & $9.6 \%$ \\
\hline \multirow{2}{*}{ Size of the municipality } & Less than a high school diploma & $51.1 \%$ \\
of residence & Resident of a municipality with less & $48.9 \%$ \\
\hline & than 10,000 inhabitants & $63.2 \%$ \\
& Resident of a municipality with more & $36.8 \%$ \\
\hline & than 10,000 inhabitants & $47.4 \%$ \\
\hline
\end{tabular}

$\mathrm{N}=272$

\subsection{Design of the questionnaire}

The design of the closed questionnaire used for the survey was inspired by the literature on Protection Motivation Theory (Grothmann and Reusswig (2006), Poussin et al. (2014), Reynaud et al. (2013)) and by a previous exploratory stage during which semi-directive interviews were conducted with 11 inhabitants of the Aude department. The main types of precautionary measures and potential drivers of private flood mitigation were identified in a review of the literature and during this exploratory stage. The questionnaire was reviewed by five flood experts before being 
completed by the respondents. It aimed at investigating individual flood mitigation and its relationships with perceptions, emotions, experience, and sociodemographic characteristics.

\subsection{Data}

\section{Private flood mitigation}

The semi-directive interviews led to the identification of 11 main measures that are detailed in appendix A and that we classified in two groups: structural and non-structural measures. Structural measures are defined here as features of the structure of homes, such as raised ground floors or raised crawl spaces, whose aim is to prevent the negative consequences of floods. Non-structural measures refer to all other measures taken to avoid damage caused by floods. Pumps and watertight doors are two examples.

For each of the 11 measures selected, the respondents stated whether it was present or not in their home and whether they intended to implement it. ${ }^{3}$ In the case a precautionary measure was present in a respondent's home, he/she had to say whether the measure had been installed by the household or by someone else.

Among the 272 households, $78 \%$ had at least one precautionary measure ${ }^{4}, 42 \%$ had implemented at least one measure themselves, and 25\% considered taking at least one measure at the time of the survey.

The potential drivers of private flood mitigation examined in this article are the components of the Protection Motivation Theory. These variables are described in more detail below and in Table 2. We also investigated the effect of the sociodemographic features listed in Table 1.

\section{Components of the Protection Motivation Theory}

\section{Threat appraisal}

The threat appraisal component of the Protection Motivation Theory comprises two variables related to the respondents' perceptions, their perceived probability of floods and their perceived consequences, and one emotion variable, which is the worry floods generate in people who feel exposed to them. Hence, in the survey, we estimated these three variables.

The perceived probability was measured by asking the respondents to indicate their perceived likelihood that their municipality will be flooded within 10 years from the time of the survey. In response to this question, respondents had to give a score on a qualitative scale from "a: impossible" to "k: certain" and also to provide a probability in terms of percentages. Qualitative perceived probabilities are used

\footnotetext{
${ }^{3}$ Note that all respondents answered these questions and a "don't know" response option was not available.

${ }^{4}$ This percentage includes households that have taken at least one measure themselves and households that only have measures which have been taken by someone else before they moved into their accommodation.
} 
in the subsequent analyses because the response rate was higher with this method than when people had to estimate probabilities ( $84 \%$ vs. $64 \%$ for the initial sample of 331 respondents). The qualitative perceived probabilities were recoded from 1 , which corresponds to "a: impossible", to 11, which is equivalent to "k: certain". On average, the perceived probability is rather high within the sample since it rates at 6.9 out of 11 . By comparison, the probability stated by the households in terms of percentages is on average $55 \% .^{5}$

The respondents were told that the survey considered a municipality is flooded when the water accumulates in its streets. According to this definition, all the inhabitants are not necessarily affected when a flood occurs in their municipality. Thus, the respondents estimated the likelihood that the water would reach their street in the case of a flood in order to provide insights into their perceived consequences of such events. This question was rated on the same scale as the qualitative perceived probability and was recoded in a similar way. Its average score of 7.0 suggests that the respondents tended to believe that they could be personally affected by floods.

Finally, the respondents stated the extent to which they worried about floods on a scale from "0: not at all" to "3: a lot". The mean value for this question was 1.6, which means that the respondents were on average between "not really" and "a little bit" worried about the risk of flooding. Among the respondents, 17\% declared that they did not worry at all about floods, $29 \%$ that they were not really worried, $31 \%$ were slightly worried, and $23 \%$ were very worried.

\section{Coping appraisal}

The coping appraisal results from the combination of the perceived self-efficacy, the perceived efficacy of the precautionary measure, and the perceived cost of the measure. We only used information regarding the perceived self-efficacy and the perceived efficacy of the measure because only $8 \%$ of all the respondents indicated perceived costs.

Perceived self-efficacy was estimated by asking the respondents to indicate their agreement with the following statement: "I do not believe that I am able to avoid the consequences of floods in my household. I have no control over such events." The respondents could rate this statement between 0 ("strongly agree") and 6 ("strongly disagree"). The average score for this item was 2.28. This indicates that the respondents in general felt rather helpless in the face of floods.

Next, the respondents assessed the efficacy of each of the 11 selected measures to protect a household against floods from 0 ("not at all effective") to 4 ("very effective"). The mean score among all measures is 2.57 , that is to say between "moderately effective" and "effective". The three precautionary measures considered to be the most effective were the measures to improve the flow of flood water, raised ground floors or raised crawl spaces, and the storage of valuables upstairs. All these measures were seen on average as "effective". The mean perceived efficacy is used in subsequent analyses because we wanted to investigate the determinants of the

\footnotetext{
${ }^{5} 208$ households provided a probability in terms of percentage.
} 
adoption of precautionary measures in general rather than the determinants of the adoption of each specific measure.

\section{Threat experience appraisal and reliance on public flood protection}

Threat experience appraisal was estimated in two steps: first, the respondents indicated whether they had already experienced at least one flood or not. If they had, they answered questions related to a reference event. ${ }^{6}$ In particular, they assessed the seriousness of the flood for their household on a scale from 0 ("not serious at all") to 10 ("extremely serious"). The threat experience appraisal variable consists of the scores given to this question by the respondents who had already experienced a flood and is set at 0 for the others. Among the 272 respondents, $81 \%$ had already experienced a flood at the time of the survey. The average score of the threat experience appraisal is 3.93 .

The reliance on public flood protection was investigated by asking the respondents to rate their satisfaction with the public management of floods in their municipality on a scale from 0 ("not at all satisfied") to 4 ("very satisfied"). The average value of this variable was 2.21. In other words, the average reliance on public flood protection was between "neither dissatisfied nor satisfied" and "satisfied". More specifically, among the 272 respondents, $47 \%$ stated they were satisfied or very satisfied with the public management of floods in their municipality, $22 \%$ were not at all satisfied or not satisfied, and $32 \%$ were neither unsatisfied nor satisfied.

\footnotetext{
${ }^{6}$ The reference event was the flood that occurred in the Aude department in 1999 for those of the inhabitants who had experienced it, the flood that occurred in 2010 for people living in the Var department who experienced it, or the flood that had the greatest impact on the respondents who were not present during either the 1999 nor the 2010 flood events.
} 
Table 2: Summary of data

\begin{tabular}{|c|c|c|c|}
\hline Variable & $\begin{array}{c}\text { Mean } \\
\text { (Std dev.) }\end{array}$ & Question & Scale \\
\hline $\begin{array}{l}\text { Perceived } \\
\text { probability }\end{array}$ & $\begin{array}{c}6.94 \\
(3.07)\end{array}$ & $\begin{array}{c}\text { "How do you assess the following } \\
\text { scenario: 'your municipality will be } \\
\text { flooded at least once in the next } 10 \\
\text { years'?" }\end{array}$ & $\begin{array}{l}\text { From } 1 \text { ("impossible") } \\
\text { to } 11 \text { ("certain") }\end{array}$ \\
\hline $\begin{array}{l}\text { Perceived } \\
\text { conse- } \\
\text { quences }\end{array}$ & $\begin{array}{l}7.01 \\
(3.73)\end{array}$ & $\begin{array}{l}\text { "In the case of flooding, how do you } \\
\text { assess the following scenario: 'the water } \\
\text { will reach your street'? " }\end{array}$ & $\begin{array}{l}\text { From } 1 \text { ("impossible") } \\
\text { to } 11 \text { ("certain") }\end{array}$ \\
\hline Worry & $\begin{array}{c}1.60 \\
(1.02)\end{array}$ & $\begin{array}{l}\text { "Are you worried about the risk of } \\
\text { flooding in your municipality ?" }\end{array}$ & $\begin{array}{l}\text { From } 0 \text { ("not at all") } \\
\text { to } 3 \text { ("a lot") }\end{array}$ \\
\hline $\begin{array}{l}\text { Perceived } \\
\text { self efficacy }\end{array}$ & $\begin{array}{c}2.28 \\
(1.67)\end{array}$ & $\begin{array}{l}\text { "To what extent do you agree with the } \\
\text { following statement: 'I do not believe } \\
\text { that I am able to avoid the consequences } \\
\text { of floods in my household. I have no } \\
\text { control over such events.'?" }\end{array}$ & $\begin{array}{c}\text { From } 0 \\
\text { ("strongly agree") } \\
\text { to } 6 \\
\text { ("strongly disagree") }\end{array}$ \\
\hline $\begin{array}{l}\text { Perceived } \\
\text { efficacy of } \\
\text { the measure }\end{array}$ & $\begin{array}{c}2.57 \\
(0.81)\end{array}$ & $\begin{array}{l}\text { "For each measure listed below, how } \\
\text { effective do you think it will be in } \\
\text { preventing the negative consequences of } \\
\text { floods?" }\end{array}$ & $\begin{array}{c}\text { From } 0 \\
\text { ("not at all effective") } \\
\text { to } 4 \\
\text { ("very effective") }\end{array}$ \\
\hline $\begin{array}{l}\text { Threat } \\
\text { experience } \\
\text { appraisal }\end{array}$ & $\begin{array}{c}3.93 \\
(3.67)\end{array}$ & $\begin{array}{c}\text { "How do you assess the seriousness of the } \\
\text { consequences of the reference flood for } \\
\text { your household?" }\end{array}$ & $\begin{array}{l}\text { From } 0 \text { ("not serious } \\
\text { at all" or for people } \\
\text { who have not } \\
\text { experienced a flood) } \\
\text { to } 10 \text { ("extremely } \\
\text { serious") }\end{array}$ \\
\hline $\begin{array}{l}\text { Reliance on } \\
\text { public flood } \\
\text { protection }\end{array}$ & $\begin{array}{c}2.21 \\
(1.06)\end{array}$ & $\begin{array}{l}\text { "Are you satisfied with the public } \\
\text { management of floods in your } \\
\text { municipality?" }\end{array}$ & $\begin{array}{l}\text { From } 0 \text { ("not at all } \\
\text { satisfied") to } 4 \\
\text { ("very satisfied") }\end{array}$ \\
\hline
\end{tabular}

$\mathrm{N}=272$

\subsection{Statistical treatment}

\section{Construction of the variables}

Two binary dependent variables were created. The first one, "implemented" takes the value 1 if at least one precautionary measure has been implemented by the household and 0 otherwise; the second dependent variable, "planned" takes the value 1 if the household was considering taking at least one precautionary measure at the time of the survey and 0 otherwise. ${ }^{7}$

\footnotetext{
${ }^{7}$ The number of measures taken or planned could have been used as dependent variables. However, since some measures could be regarded as substitute (Osberghaus, 2015), their accumulation is not relevant to explore the willingness to mitigate flood consequences.
} 
In addition, we modified some explanatory variables.

First, to avoid multicollinearity, we checked that the Spearman coefficients of correlation were all inferior to 0.80 (Bryman and Cramer, 1990). Actually, the highest correlation found was 0.46 between perceived consequences and perceived probability (see Appendix B). Since this correlation is rather high, we chose to follow Grothmann and Reusswig (2006) and to define the threat appraisal variable as the joint measurement of perceived probability and perceived consequences. More specifically, the perceived probability was normalized to between 0 and 1 before being multiplied by the normalized perceived consequences. ${ }^{8}$ As a result, the threat appraisal variable takes its values between 0 and 1 .

Second, since "worry" and "reliance on public flood protection" were defined on four-point and five-point scales, we chose not to treat them as continuous variables and consequently transformed them into binary variables. In subsequent analyses, "worry" takes the value 0 for respondents who stated they did not worry at all or were not really worried about floods and 1 for respondents who stated they were slightly or very worried about floods. Similarly, "reliance on public flood protection" takes the value 0 for respondents who stated they were not at all satisfied, not satisfied or neither satisfied nor unsatisfied with the public management of floods and 1 for respondents who stated they were satisfied or very satisfied with the public management of floods.

Finally, the coping appraisal variables ("perceived self-efficacy" and "perceived efficacy of measures") are defined on seven-point likert scales. Thus, we chose to treat them as categorical variables. In order to limit the number of categories, we created three of them for each variable: the first category contains the answers below 2 (2 excluded). We call this category "low perceived self efficacy" or "low perceived efficacy of measures". The second category contains the answers ranging from 2 to 4 included. We call this category "medium perceived self efficacy" or "medium perceived efficacy of measures". The third category contains the answers above 4 (4 excluded). We call this category "high perceived self efficacy" or "high perceived efficacy of measures". Notice that no respondent rated the variable "perceived efficacy of the measures" higher than 4. Consequently, the category "high perceived efficacy of measures" is empty and does not appear in subsequent analyses.

\section{Regressions and tests}

First, two logistic regressions (Train, 2009) were performed to compare the adequacy of the Protection Motivation Theory for each dependent variable. To examine the role of measures that had already been taken in the planning of new measures, we conducted a robustness check by performing a third logistic regression on "planned" without the respondents who had already taken at least one measure. We then investigated a potential feedback effect by comparing the perceptions of people who had already taken at least one precautionary measure with the perceptions of respondents who had not yet taken any measure but were considering doing so at the

\footnotetext{
${ }^{8}$ Thus Threat appraisal $=\frac{\text { Perceived } \text { consequences }}{11} * \frac{\text { Perceived probability }}{11}$
} 
time of the survey. Since the data were not normally distributed, Mann-WhitneyWilcoxon tests (Mann and Whitney, 1947) were used to compare the two samples. As most of the respondents who planned to take measures lived in the Var department, we checked whether the difference between the two groups could be explained by the department of residence rather than a feedback effect by conducting the same tests on respondents from the Var only.

Finally, we focused on the variable which is the best explained by the Protection Motivation Theory ("planned") and examined the role of sociodemographic features in order to expand this framework.

In this paper, we set the significance level at 0.1 for all tests.

\section{Results}

\subsection{Scope of the Protection Motivation Theory}

Table 3 summarizes the results of three logistic regressions. Model 1 and Model $2 \mathrm{~A}$ were estimated using the whole sample. Model 1 explains the implementation of at least one precautionary measure whereas Model 2A explains the willingness to take at least one measure. The two model specifications contain the Protection Motivation Theory variables presented above. The fit of Model $2 \mathrm{~A}$ is much better than that of Model 1 (Nagelkerke $\mathrm{R}^{2}$ of 0.308 versus 0.106 ). Furthermore, only two variables, "high perceived self-efficacy" and "threat experience appraisal", are significant in Model 1 whereas only "worry" and "low perceived efficacy of measures" are not significant in Model 2A.

In Model 2A, as the Protection Motivation Theory would lead one to expect, "threat appraisal" and "threat experience appraisal" positively influence the willingness to take precautionary measures. However, "reliance on public flood protection" has a positive effect, whereas in the Protection Motivation Theory, there is a negative relationship between this variable and the willingness to implement precautionary measures. In addition, the effect of one of the variables used to assess coping appraisal, "perceived self-efficacy", is complex. Indeed, respondents with either a very low or a very high perceived self-efficacy are less likely to be willing to take precautionary measures than people with a medium perceived self-efficacy.

Model 2B is the same as Model 2A but was estimated using only the responses of people who had not yet taken any measures. Thus, it provides a robustness check for Model 2A which examines the role of "implemented" in the willingness to take further measures. Compared to Model 2A, all the coefficients of Model 2B have the same sign. However, "low perceived self-efficacy", "high perceived self-efficacy", and "reliance on public flood protection" are no longer significant. This could be due to the reduced size of the sample used. Since Model 2A and Model 2B are qualitatively similar (all the coefficients have the same sign), we can reasonably assume that the variable "implemented" does not have a major effect on the variable "planned". Thus, our results suggest that the potential role of the measures already taken is not decisive in explaining the better fit of Model 2A compared to Model 1. 
Table 3: Comparison of the adequacy of the Protection Motivation Theory for implemented and planned precautionary measures using multiple logistic regressions

\section{Model 1: $\quad$ Model 2A: \\ Implemented Planned \\ Model 2B: \\ (whole sample) (whole sample) (no implementation) \\ Planned}

\begin{tabular}{|c|c|c|c|}
\hline Variable & $\begin{array}{l}\text { Estimate } \\
\text { (Std dev.) }\end{array}$ & $\begin{array}{l}\text { Estimate } \\
\text { (Std dev.) }\end{array}$ & $\begin{array}{l}\text { Estimate } \\
\text { (Std dev.) }\end{array}$ \\
\hline Intercept & $\begin{array}{c}-1.24^{* * *} \\
(0.35)\end{array}$ & $\begin{array}{c}-3.08^{* * *} \\
(0.50)\end{array}$ & $\begin{array}{c}-3.37^{* * *} \\
(0.70)\end{array}$ \\
\hline Threat appraisal & $\begin{array}{c}0.58 \\
(0.43)\end{array}$ & $\begin{array}{c}1.61^{* * *} \\
(0.53)\end{array}$ & $\begin{array}{c}2.39^{* * *} \\
(0.77)\end{array}$ \\
\hline Worry & $\begin{array}{c}0.15 \\
(0.30)\end{array}$ & $\begin{array}{c}0.49 \\
(0.38)\end{array}$ & $\begin{array}{c}0.42 \\
(0.54)\end{array}$ \\
\hline Low perceived self-efficacy & $\begin{array}{c}0.30 \\
(0.28)\end{array}$ & $\begin{array}{r}-0.62^{*} \\
(0.36)\end{array}$ & $\begin{array}{l}-0.62 \\
(0.52)\end{array}$ \\
\hline High perceived self-efficacy & $\begin{array}{l}1.0^{* *} \\
(0.40)\end{array}$ & $\begin{array}{c}-1.46^{* *} \\
(0.60)\end{array}$ & $\begin{array}{l}-1.29 \\
(1.16)\end{array}$ \\
\hline Low perceived efficacy of measures & $\begin{array}{c}0.28 \\
(0.34)\end{array}$ & $\begin{array}{l}-0.30 \\
(0.50)\end{array}$ & $\begin{array}{l}-0.51 \\
(0.82)\end{array}$ \\
\hline Threat experience appraisal & $\begin{array}{c}0.09^{* *} \\
(0.04)\end{array}$ & $\begin{array}{c}0.19^{* * *} \\
(0.05)\end{array}$ & $\begin{array}{c}0.18^{* *} \\
(0.07)\end{array}$ \\
\hline $\begin{array}{l}\text { Reliance on public flood } \\
\text { protection }\end{array}$ & $\begin{array}{l}-0.19 \\
(0.27)\end{array}$ & $\begin{array}{c}0.77^{* *} \\
(0.35)\end{array}$ & $\begin{array}{c}0.55 \\
(0.50)\end{array}$ \\
\hline Nagelkerke $\mathbf{R}^{2}$ & 0.106 & 0.308 & 0.359 \\
\hline
\end{tabular}

Model 1 and Model 2A: N=272 (whole sample); Model 2B: $\mathrm{N}=157$ (the sample used consists of the respondents who have never taken a precautionary measure). The category of reference for "perceived self-efficacy" is "medium perceived self-efficacy" and the category of reference for "perceived efficacy of measures" is "medium perceived efficacy of measures". Significance levels: ${ }^{*} \mathrm{p}<0.1$; $^{* *} \mathrm{p}<0.05 ;{ }^{* * *} \mathrm{p}<0.01$.

These results have two main implications. First, measures that have already been taken and planned measures cannot be used equivalently to explore private flood mitigation mechanisms for the sample considered. Secondly, the Protection Motivation Theory explains the willingness to take precautionary measures better than the presence of already implemented measures in the household in our case. 


\subsection{Feedback effect of the fact precautionary measures have been taken}

To explore the possible feedback effect of the fact precautionary measures have been taken, the scores for the perception variables of respondents who had already taken precautionary measures were compared with those of people who planned to take at least one measure. To do so, we first isolated two groups within the sample: Group 1 consisted of respondents who considered taking at least one measure and had not taken any precautionary measure at the time of the survey, and Group 2 consisted of respondents who had already taken at least one measure. Mann-Whitney-Wilcoxon tests were then performed between the distributions of the Protection Motivation Theory variables in Group 1 and Group 2. Since most respondents in Group 1 lived in the Var department, which was hit by a major flash flood 11 years later than the Aude department, we checked whether the differences in the two groups came from this unbalanced distribution by undertaking the same comparison considering only respondents from the Var department. Table 4 lists the means of the variable for which the tests were significant at the level 0.1 for the two groups.

Table 4: Comparison of the Protection Motivation Theory variables between respondents who had already taken precautionary measures and respondents who intended to take measures at the time of the survey.

\begin{tabular}{lll}
\hline Variable & Group 1 & Group 2 \\
\hline $\begin{array}{l}\text { Mean threat appraisal for the two departments } \\
\quad \text { (Group 1: } \mathrm{N}=34 \text {; Group 2: } \mathrm{N}=115)\end{array}$ & $0.66^{* *}$ & $0.51^{* *}$ \\
$\begin{array}{l}\text { Mean threat appraisal for the Var department } \\
\quad \text { (Group 1: } \mathrm{N}=27 \text {; Group 2: } \mathrm{N}=54)\end{array}$ & $0.74^{* *}$ & $0.53^{* *}$ \\
\hline
\end{tabular}

Group 1: People who considered taking at least one precautionary measure but had not taken any precautionary measure at the time of the survey; Group 2: People who had already taken at least one precautionary measure at the time of the survey. The significance levels come from Mann-Whitney-Wilcoxon tests between group 1 and group 2. Significance levels: ${ }^{*} \mathrm{p}<0.1 ;{ }^{* *} \mathrm{p}<0.05 ;{ }^{* * *} \mathrm{p}<0.01$.

On average, people who had already taken at least one measure have a lower score on the threat appraisal variable than the respondents who planned to take at least one measure. These results were obtained not only when respondents from the two departments were taken into consideration, but also when only the respondents in the Var were taken into account. Thus, this result was not mainly due to the fact that people in group 1 had experienced a major flood more recently than people in group 2. Consequently, these results support the assumption of a feedback effect of taking precautionary measures on perceptions relating to flood risks.

It thus appeared to us to be more relevant to focus on planned measures than on measures that had already been taken to explore the mechanisms of private flood mitigation. Consequently, the variable "planned" was used to broaden the Protection Motivation Framework by exploring the effect of local social interactions and to examine the role of several sociodemographic features in private flood mitigation. 


\subsection{Effect of sociodemographic features}

All the variables of the Protection Motivation Theory taken into account in Model $2 \mathrm{~A}$ were used as explanatory variables in Model 3, which is presented in Table 5. Compared to Model 2A, "threat appraisal" and "threat experience appraisal" have the same sign and similar magnitude. However, "low perceived self-efficacy", "high perceived self-efficacy", and "reliance on public flood protection" are no longer significant at the 0.1 level. Regarding the sociodemographic variables, the respondents who had at least a high school diploma, those who lived in the Var department and in municipalities with more than 10,000 inhabitants, and home owners are more likely to consider taking at least one precautionary measure than the others.

Table 5: Multiple logistic regression of the variable "planned"

Model 3

\begin{tabular}{cccc}
\hline Variable & Estimate & Std dev. & $\begin{array}{c}\text { Marginal effect or } \\
\text { Marginal } \text { effect }{ }^{*} \text { Std } \text { dev } .\end{array}$ \\
\hline Intercept & $-5.34^{* * *}$ & 0.94 & \\
Block 1: Socio-Psychological & variables from & the Protection Motivation Theory \\
Threat appraisal & $1.61^{* * *}$ & 0.60 & 0.05 \\
Worry & 0.29 & 0.47 & 0.03 \\
Low perceived self-efficacy & -0.27 & 0.42 & -0.02 \\
High perceived self-efficacy & -1.05 & 0.69 & -0.07 \\
Low perceived efficacy of measures & -0.12 & 0.56 & -0.01 \\
Threat experience appraisal & $0.20^{* * *}$ & 0.06 & 0.07 \\
Reliance on public flood protection & 0.57 & 0.41 & 0.07 \\
Nagelkerke R $\mathbf{R}^{\mathbf{2}}$ for this block & $\mathbf{0 . 3 0 8}$ & & \\
Block & 2: & Socio-economic variables & 0.20 \\
Education level & $1.29^{* * *}$ & 0.41 & 0.08 \\
Municipality size & $1.34^{* * *}$ & 0.41 & 0.18 \\
Ownership of the home & $1.22^{* * *}$ & 0.43 & 0.07 \\
Age & $1.15^{* *}$ & 0.48 & -0.00 \\
Department (0: Aude; Var) & -0.02 & 0.01 & 0.02 \\
Gender (0: Female; 1: Male) & 0.19 & 0.37 & \\
Nagelgerke R ${ }^{\mathbf{2}}$ change & $+\mathbf{0 . 1 9 4}$ & & \\
\hline Nagelkerke R $\mathbf{R}^{\mathbf{2}}$ final & $\mathbf{0 . 5 0 2}$ & & \\
\hline
\end{tabular}

$\mathrm{N}=272$. The marginal effects are the partial effect for the median observation. The category of reference for "perceived self-efficacy" is "medium perceived self-efficacy" and the category of reference for "perceived efficacy of measures" is "medium perceived efficacy of measures". Significance levels: ${ }^{*} \mathrm{p}<0.1 ; * * \mathrm{p}<0.05 ;{ }^{* * *} \mathrm{p}<0.01$.

Marginal effects at the median are also shown. All the marginal effects of the sociodemographic variables lie between -0.00 and 0.20 . Having at least a high school diploma increases the probability of considering taking measures by $20 \%$ when all variables are at the median, which is the greatest marginal effect. On the other 
hand, the smallest marginal effect is associated to the age of the respondent, which does not influence the probability of considering taking measures.

The significant variables in Block 1 ("threat appraisal" and "threat experience appraisal") are treated as continuous and lie on different scales. As a result, we cannot directly compare their marginal effects. Thus, for each variable, we multiplied its marginal effect at the median by its standard deviation in order to obtain the consequence of increasing the variable by one standard deviation. We observe that the probability of considering taking measures increases by $7 \%$ if "threat experience appraisal" increases by one standard deviation when all other variables stay at the median and by $5 \%$ when "threat appraisal" increases by one standard deviation.

Finally, we would like to underline that the Model 3 shown in Table 5 relies on the assumption of homoskedasticity of the error terms. In order to study this assumption, we estimated an equivalent heteroskedastic model. In this model, the dependent and independent variables are the same as in Model 3, but the scale parameter is a function of all the independent variables of Model 3. We conducted a likelihood ratio test between Model 3 and its equivalent heteroskedatic model. This test shows that Model 3 has a significantly better fit than the heteroskedastic model (Log likelihood of Model 3: -95.8; Log likelihood of its equivalent heteroskedastic model: -151.8; p-value of the likelihood ratio test: $<2.2 \mathrm{e}-16)$. As a result, the assumption of homoskedasticity seems reasonable here.

\section{Discussion}

\subsection{The dynamics of adaptation and the Protection Motiva- tion Theory}

Our results suggest that the Protection Motivation Theory explains the willingness to mitigate floods better than the fact precautionary measures had already been taken by the household. Two possible reasons for this finding were identified.

First, as shown in Figure 1, there could be actual barriers which, according to the Protection Motivation Theory, prevent people from taking precautionary measures. Since we did not control for these actual barriers, their effect might be included in the error terms of Model 1 and be greater for people who did not take any precautionary measure than for the others. In that case, the key assumption of independence of error terms would be violated and the estimation of the parameters distorted (Train, 2009). In contrast, Model $2 \mathrm{~A}$ aims to describe the motivation to protect oneself, which, according to the Protection Motivation Theory, does not depend on actual barriers (see Figure 1). Note that theoretically, the presence of actual barriers implies that all the respondents who intend to take precautionary measures will not necessarily do so. Therefore, it is consistent that the perception and emotion variables of the Protection Motivation Theory, which are assumed to directly affect the protection motivation, explain the intention to take precautionary measures better than the actual implementation of such measures, which is assumed to also depend on actual barriers. 
Secondly, the perceptions which led to the decision to take precautionary measures can change over time. Thus, the data we collected may not accurately depict the state of mind that led the respondents who implemented precautionary measures to take action to mitigate the consequences of floods. According to Bubeck et al. (2012), these changes can occur due to a feedback effect after a precautionary measure has been taken.

We explored this possibility by comparing the threat appraisal of the respondents who had already taken precautionary measures and those of the respondents who intended to take measures at the time of the survey. Indeed, under the assumption that the Protection Motivation Theory is a generalizable framework, the same pattern of perceptions as the one observed for people who intended to implement measures should have led the respondents who had already taken precautionary measures to do so. Nevertheless, it appears that people who had already taken measures had a lower threat appraisal than people who intended to take mitigation actions. This effect was found when considering respondents from both departments and only respondents from the Var department, who had experienced a major flood more recently than people from the Aude department. Thus, the difference in threat appraisal between the two groups is not mainly due to the time between the survey and the last major flood. As a result, this observation supports the assumption that risk perception tends to decrease after precautionary measures have been taken.

We acknowledge that the samples we used in the Mann-Whitney-Wilocoxon tests are rather small but our test statistics is adapted to small sample sizes. ${ }^{9}$ Moreover, since we used a cross-section dataset, the difference in observed perceptions could be due to differences in the characteristics of the individuals rather than to having taken precautionary measures. Ideally, panel data should be used in order to isolate the effect of the implementation of a precautionary measure. Unfortunately, we do not have this kind of data. Another caveat of our study is that it relies on stated data. In particular, some respondents could have stated that they planned to take precautionary measures to please the interviewer or to make a good impression on the interviewer. As a result, the variable "planned" could be biased. However, our analysis highlights the importance of considering planned measures in addition to implemented ones when investigating the relationships between socio-psychological variables and private flood mitigation.

More generally, our results highlight the importance of considering the dynamic aspect of adaptation to floods. Indeed, since explanatory factors (such as threat appraisal) may change over time, particular care should be taken to distinguish between the variables which may evolve and those which are stable (e.g., gender) when designing a survey to explore private flood mitigation and interpreting its results. In addition, if a factor only temporarily affects an individual's willingness to take precautionary measures, advisory policies that target this factor to foster flood mitigation should be timed accordingly.

\footnotetext{
${ }^{9}$ We have checked our results on a bootstrap of 500 observations and found that the same conclusion holds.
} 


\subsection{Determinants of private flood mitigation in France}

\section{Threat appraisal, experience, coping appraisal, and reliance on public flood protection}

Looking more specifically at the drivers of private flood mitigation, threat appraisal has the expected positive effect. This result is in line with the study of Grothmann and Reusswig (2006).

The positive effect of experience also appears in the wider literature (e.g. Grothmann and Reusswig (2006), Osberghaus (2015)). However, our study also has the particularity of examining the situation in two areas: the Aude department, in which an over 100-year flood occurred in 1999, and the Var department, which was affected by an over 100-year flood in 2010. Because of this contrasted temporal distance to major events, we can isolate the importance of recent experience in explaining intentions to take precautionary measures. We found that living in the Var department increased the intention to take precautionary measures compared to living in the Aude department, whereas -on the contrary- the decision to actually take measures was not explained by the geographical variable. Thus, it appears that there is still an ongoing process of adaptation to floods five years after the most recent striking event in the Var department, whereas sixteen years after the 100 year flood, the situation appeared to be more stable in the Aude department. In other words, the department variable could be a proxy for the temporal distance to the most recent major flood in our survey and its effect on private flood mitigation might evolve over time.

The complex effect of perceived self-efficacy in Model 2A is another striking result. The Protection Motivation Theory predicts that people with very low coping appraisal will be less likely to take mitigation actions than the others. In our sample, respondents with very low but also very high "perceived self-efficacy" tended to be less willing to take precautionary measures than the others. One possible explanation for this result is that respondents with a high coping appraisal could have taken measures faster than the others since this task seems easy for them. As a result, these people could have already taken measures at the time of our survey and are consequently not willing to take additional precautionary measures. This assumption is supported by Model 1 and by the results of Grothmann and Reusswig (2006) according to which respondents with a high perceived self-efficacy were the most likely to have already taken precautionary measures at the time of the surveys. Nevertheless, to further explore the hypothesis that coping appraisal is an accelerator rather than a necessary condition for adaptation to floods, the long term evolution of its effect on the implementation of measures should be examined to see if it decreases over time. ${ }^{10}$ Moreover, since "perceived self-efficacy" is not significant to explain the intention to take precautionary measures in Model 3, its complex effect found in Model 2A may not be very robust.

Finally, reliance on public flood protection has a positive effect on private flood

\footnotetext{
${ }^{10}$ High coping appraisal could also make people more confident in their ability to face the risk without implementing precautionary measures (see Krueger and Dickson (1994)). We found no evidence for a link between risk taking and coping appraisal in our sample.
} 
mitigation in Model 2A and no significant effect in Model 3. However, according to the Protection Motivation Theory and as supported by the results of Grothmann and Reusswig (2006), this variable should reduce people's willingness to take precautionary measures. On the other hand, Reynaud et al. (2013) found a positive relationship between the level of confidence in the city to efficiently manage flood risks and the presence of a pump in the household. Similarly, Poussin et al. (2014) found a positive effect of the feeling of being protected by public measures on the number of structural measures implemented. Thus, the relationship between reliance on public flood protection and private mitigation is still unclear and requires further investigation.

\section{Sociodemographic variables: education level, department, size of the mu- nicipality, and ownership of the home}

The respondents who had at least a high school diploma, those who lived in the Var department or in a municipality with more than 10,000 inhabitants, and home owners have a higher probability of considering taking precautionary measures. The positive effect of home ownership is in line with the results obtained by Grothmann and Reusswig (2006) and Poussin et al. (2014). In addition, the positive effect of education level has been found in other studies (Poussin et al., 2014, Reynaud et al., 2013). Moreover, as discussed above, the department variable could be a proxy of the temporal distance to the most recent major event. The effect of the size of the municipality could be explained by the fact that the need for private protection is greater in big towns than in small municipalities. Indeed, the need for private protection is greater in big cities, where only $71 \%$ of the respondents have at least one measure in their household, than in smaller cities, where $85 \%$ of the respondents have at least one measure in their household. This result is in line with the results obtained by Bubeck et al. (2013), who found that inhabitants of urban areas are less likely to purchase flood insurance than inhabitants of rural areas. Similarly, Botzen et al. (2009) found that people living in rural areas have more positive attitudes towards flood mitigation than people who live in urban areas and Osberghaus (2015) found a significant negative correlation between flood mitigation and the population of the municipality of residence. Finally, both the effect of the size of the municipality and the department of residence may be linked to institutional contexts and social networks, which we were unable to investigate in depth in our study but were examined by Bachner et al. (2016), Haer et al. (2016), and Reynaud et al. (2013) for example.

\section{Other potential determinants: risk aversion, income, and solidarity schemes}

One common hypothesis in the economic literature on mitigation is that higher levels of risk aversion lead to higher likelihoods of mitigation and to more extensive investments in mitigation. Carson et al. (2013) found evidence that supports this hypothesis in a study on 173,000 individuals participating in a public program on mitigation measures in Florida. Building on the domain-specific risk-attitude approach of Weber et al. (2002), we collected data from which we constructed an 
indicator of risk aversion with respect to flood risks. However, too few respondents answered this question and we preferred not to reduce the size of our sample.

A similar problem arose with the data on income: only half of our sample stated their income so we decided not to include this variable in our analyses. However, the impact of income (or wealth) on risk aversion is widely discussed in the literature (see for example Brunnermeier and Nagel (2008), Cohn et al. (1975)). Moreover, income may also directly influence mitigation decisions as mitigation investments can be costly. For instance, in our survey, among the respondents who had not taken any measure and did not intend to do so (63 people out of 331), 24\% explained this decision by the fact that precautionary measures are too costly. Similarly, in a qualitative survey conducted in the United States, Carlson et al. (2014) found that the most often cited constraints to explain the difficulty of adapting storm water management to climate change were economic concerns. Nevertheless, empirical evidence on the effect of income is mixed, as discussed by Carson et al. (2013).

Finally, private precautionary measures can also be considered as self-insurance (Carson et al. 2013). As a result, they can be substitutes for market insurance or governmental relief programs, in which case the latter might crowd out the former, as has been shown in several countries (Raschky et al., 2013). In other words, individuals would refrain from investing in self-insurance and rather count on market insurance or public support. Because there is a compulsory insurance system for home owners in France (Erdlenbruch et al., 2009, Grislain-Letrémy and Peinturier, 2010), we could not thoroughly investigate the relationship between self-insurance and market insurances. However, more than two thirds of our sample had at least one precautionary measure in their home and nearly half of the respondents had taken themselves at least one measure. This means that the public solidarity scheme does not completely crowd out individual measures. This is in line with the results obtained by Carson et al. (2013) and Osberghaus (2015), who did not find any substitutability between individual mitigation and market insurance.

\section{Conclusion}

The main findings of our study are summarized in Figure 3. In particular, our results suggest that the Protection Motivation Theory is an appropriate framework to explain private flood mitigation in France and that there could be a feedback effect of past investments on threat appraisal. Taking this feedback effect into account could improve the assessment of the determinants of households' flood mitigation and thus guide the design of policies aimed at fostering private actions. For instance, it could be efficient to help people who intend to take measures shortly after major floods, when risk perceptions are still high, and then to try and maintain flood awareness and preparedness.

To design policies to support those who intend to take precautionary measures, additional issues that are not addressed in our study could be examined. In particular, we did not take potential actual barriers into account. However, according to the Protection Motivation Theory, they explain the difference between intentions and decisions to mitigate. Actual barriers could be the high cost of investing in mitigation 
measures or high information costs to discover the most suitable behavior. The findings of Poussin et al. (2014) support the assumption that lack of financial resources could hinder private mitigation. They indeed suggest that incentives from the state or municipalities have a positive impact on intentions to mitigate in France. ${ }^{11}$ Even if the state does not provide financial aid, it could provide information on the cost effectiveness of mitigation investments in different hazard zones (see Kreibich et al. (2011) for data in Germany). As a result, policies aimed at increasing self-insurance should probably work toward removing actual barriers for those individuals who are motivated to invest. Our study helped identify this group. Subsequent research could investigate the nature of actual barriers in more depth, which would facilitate the design of public support for individual precautionary measures.

Finally, one interesting question is whether adjusting the public CatNat insurance system would increase individual mitigation investments. Investigating this question would require measuring the elasticity of substitution of the two insurance tools to investigate how much more investment in precautionary measures could be triggered by a reduction in the CatNat premium (see Botzen et al. (2009) and Wouter Botzen and Van Den Bergh (2012)). To extend this idea, it is worth highlighting that some private precautionary measures can even improve the situation of larger communities in the face of natural hazards, as discussed by Carlson et al. (2014) in the context of storm water management. Thus, it would be useful to identify such measures in the context of floods and to encourage their implementation in order to increase the efficiency of private mitigation compared to public protection, which can be harmful to the environment.

\footnotetext{
${ }^{11}$ We asked the respondents to say whether they have been subsidized or not but only very few of our respondents (4 people out of the whole sample) obtained public support for their investments. As a result, we were unable to investigate this issue.
} 


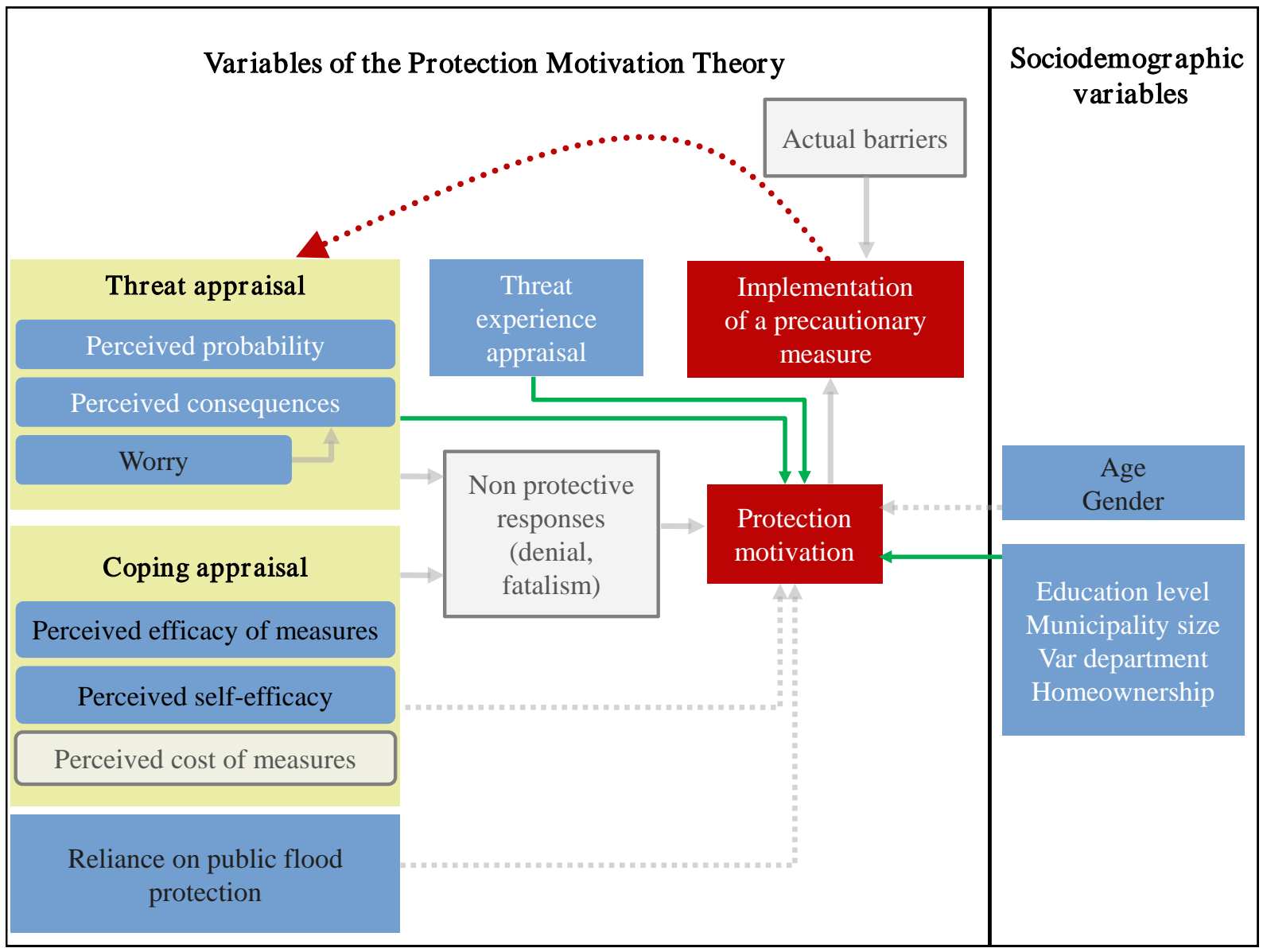

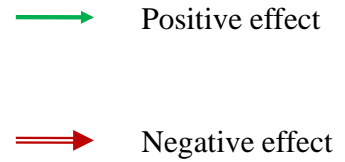

Non significant effect

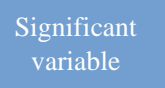

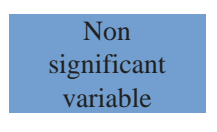
Variable not estimated

Figure 3: Summary of the factors of private flood mitigation highlighted in the analyses. 


\section{Acknowledgements}

We are grateful to our colleagues from Irstea who helped us at many stages of this work, especially to Frédéric Grelot, Pauline Brémond, Clara Therville and the members of the Retina project. We acknowledge financial support from the French Ministry of Research within the Retina project 13-MRES-RDT-2-CVS-023. We also thank EnovResearch for having carried out the face-to-face interviews.

\section{References}

Bachner, G., Seebauer, S., Pfurtscheller, C., Brucker, A., Gaillard, J., 2016. Assessing the benefits of organized voluntary emergency services-concepts and evidence from flood protection in austria. Disaster Prevention and Management: An International Journal 25 (3).

Botzen, W. J. W., Aerts, J. C. J. H., van den Bergh, J. C. J. M., 2009. Willingness of homeowners to mitigate climate risk through insurance. Ecological Economics 68 (8), 2265-2277.

Brunnermeier, M. K., Nagel, S., 2008. Do wealth fluctuations generate time-varying risk aversion? micro-evidence on individuals' asset allocation (digest summary). American Economic Review 98 (3), 713-736.

Bryman, A., Cramer, D., 1990. Quantitative Data Analysis for Social Scientists. Routledge.

Bubeck, P., Botzen, W., Kreibich, H., Aerts, J., 2013. Detailed insights into the influence of flood-coping appraisals on mitigation behaviour. Global Environmental Change 23 (5), $1327-1338$.

Bubeck, P., Botzen, W. J. W., Aerts, J. C. J. H., 2012. A review of risk perceptions and other factors that influence flood mitigation behavior. Risk Analysis 32 (9), 1481-1495.

Carlson, C., Barreteau, O., Kirshen, P., Foltz, K., 2014. Storm water management as a public good provision problem: Survey to understand perspectives of lowimpact development for urban storm water management practices under climate change. Journal of Water Resources Planning and Management 141 (6), 04014080.

Carson, J. M., McCullough, K. A., Pooser, D. M., 2013. Deciding whether to invest in mitigation measures: evidence from florida. Journal of Risk and Insurance $80(2), 309-327$.

Cohn, R. A., Lewellen, W. G., Lease, R. C., Schlarbaum, G. G., 1975. Individual investor risk aversion and investment portfolio composition. The Journal of Finance $30(2), 605-620$.

DGPR, 2011. Première évaluation national des risques d'inondation - principaux résultats. Tech. rep., Ministère de l'Ecologie, du Développement durable et de l'énergie. 
Erdlenbruch, K., Thoyer, S., Grelot, F., Kast, R., Enjolras, G., 2009. Risk-sharing policies in the context of the french flood prevention action programmes. Journal of Environmental Management 91 (2), 363 - 369.

Glenk, K., Fischer, A., 2010. Insurance, prevention or just wait and see? public preferences for water management strategies in the context of climate change. Ecological Economics 69 (11), 2279-2291.

Grislain-Letrémy, C., Peinturier, C., Mai 2010. Le régime d'assurance des catastrophes naturelles en france métropolitaine entre 1995 et 2006. Études \& documents $\mathrm{n}^{\circ}: 22$, Conseil Général du Développement Durable.

Grothmann, T., Reusswig, F., 2006. People at risk of flooding: why some residents take precautionary action while others do not. Natural Hazards 38, 101-120.

Haer, T., Botzen, W. W., Aerts, J. C., 2016. The effectiveness of flood risk communication strategies and the influence of social networks - insights from an agentbased model. Environmental Science \& Policy 60, 44-52.

Kreibich, H., Christenberger, S., Schwarze, R., 2011. Economic motivation of households to undertake private precautionary measures against floods. Natural Hazards and Earth System Sciences 11 (2), 309-321.

Kreibich, H., Thieken, A. H., Petrow, T., Müller, M., Merz, B., 2005. Flood loss reduction of private households due to building precautionary measures-lessons learned from the elbe flood in august 2002. Natural Hazards and Earth System Science 5 (1), 117-126.

Krueger, N., Dickson, P. R., 1994. How believing in ourselves increases risk taking: Perceived self-efficacy and opportunity recognition. Decision Sciences 25 (3), 385400.

Kundzewicz, Z. W., 1999. Flood protection-sustainability issues. Hydrological Sciences Journal 44 (4), 559-571.

Mann, H. B., Whitney, D. R., 1947. On a test of whether one of two random variables is stochastically larger than the other. The annals of mathematical statistics, 5060 .

Milne, S., Sheeran, P., Orbell, S., 2000. Prediction and intervention in health-related behavior: A meta-analytic review of protection motivation theory. Journal of Applied Social Psychology 30 (1), 106-143.

OECD, 2014. Seine basin, Île-de-france, 2014: Resilience to major floods. Tech. rep., OECD Publishing, Paris.

Osberghaus, D., 2015. The determinants of private flood mitigation measures in germany — evidence from a nationwide survey. Ecological Economics 110, 36-50.

Patwardhan, A., Semenov, S., Schnieder, S., Burton, I., Magadza, C., Oppenheimer, M., Pittock, B., Rahman, A., Smith, J., Suarez, A., et al., 2007. Assessing key vulnerabilities and the risk from climate change. Climate change 2007: Impacts, adaptation and vulnerability: Contribution of working group II to the fourth assessment report of the intergovernmental panel on climate change, 779-810. 
Picard, P., 2008. Natural disaster insurance and the equity-efficiency trade-off. Journal of Risk and Insurance 75 (1), 17-38.

Poussin, J. K., Botzen, W. W., Aerts, J. C., 2014. Factors of influence on flood damage mitigation behaviour by households. Environmental Science \& Policy 40, $69-77$.

Poussin, J. K., Botzen, W. W., Aerts, J. C., 2015. Effectiveness of flood damage mitigation measures: Empirical evidence from french flood disasters. Global Environmental Change 31, 74-84.

Raschky, P. A., Schwarze, R., Schwindt, M., Zahn, F., 2013. Uncertainty of governmental relief and the crowding out of flood insurance. Environmental and Resource Economics 54 (2), 179-200.

Reynaud, A., Aubert, C., Nguyen, M.-H., 2013. Living with floods: protective behaviours and risk perception of vietnamese households. The Geneva Papers on Risk and Insurance-Issues and Practice 38 (3), 547-579.

Rogers, R. W., 1975. A protection motivation theory of fear appeals and attitude change. The journal of psychology 91 (1), 93-114.

Train, K. E., 2009. Discrete choice methods with simulation. Cambridge university press.

Vinet, F., 2008. Geographical analysis of damage due to flash floods in southern france: The cases of 12-13 november 1999 and 8-9 september 2002. Applied Geography 28 (4), 323-336.

Vinet, F., Lumbroso, D., Defossez, S., Boissier, L., 2012. A comparative analysis of the loss of life during two recent floods in france: The sea surge caused by the storm xynthia and the flash flood in var. Natural Hazards 61 (3), 1179-1201.

Weber, E. U., Blais, A.-R., Betz, N. E., 2002. A domain-specific risk-attitude scale: measuring risk perceptions and risk behaviors. Journal of Behavioral Decision Making 15 (4), 263-290.

Werritty, A., 2006. Sustainable flood management: oxymoron or new paradigm? Area 38 (1), 16-23.

Wouter Botzen, W. J., Van Den Bergh, J. C. J. M., 2012. Monetary valuation of insurance against flood risk under climate change. International Economic Review 53 (3), 1005-1026. 


\section{Appendices}

\section{A Precautionary measures}

\begin{tabular}{cc}
\hline Structural measures & Non structural measures \\
\hline $\begin{array}{c}\text { Raised ground floor, raised crawl space } \\
\text { Opening on the roof to facilitate } \\
\text { evation }\end{array}$ & $\begin{array}{c}\text { Watertight doors and windows } \\
\text { Use of water resistant materials (for } \\
\text { the floor and/or the walls) } \\
\begin{array}{c}\text { Electrical wiring and systems and/or } \\
\text { boiler installed higher up in the walls }\end{array}\end{array}$ \\
& Slot-in flood barrier(s) \\
& All main rooms (kitchen, bedrooms, \\
living-room) installed upstairs \\
Measures to improve water flow \\
Valuables stored upstairs
\end{tabular}


Author-produced version of the article published in Ecological Economics, 2017, N¹31, p.342-352

The original publication is available at http://www.sciencedirect.com

Doi: 10.1016/j.ecolecon.2016.09.014

\section{B Correlations}

Table 6: Spearman correlations between the variables

\begin{tabular}{|c|c|c|c|c|c|c|c|c|c|c|c|c|c|c|}
\hline & 1 & 2 & 3 & 4 & 5 & 6 & 7 & 8 & 9 & 10 & 11 & 12 & 13 & 14 \\
\hline 1: Perceived probability & 1.00 & $0.46^{* * *}$ & $0.81^{* * *}$ & $0.39^{* * *}$ & -0.05 & 0.01 & $0.27^{* * *}$ & $-0.22^{* * *}$ & 0.02 & $-0.16^{* *}$ & $0.13^{* *}$ & 0.01 & -0.01 & 0.01 \\
\hline 2: Perceived consequences & & 1.00 & $0.87^{* * *}$ & $0.36^{* * *}$ & -0.01 & $0.15^{* *}$ & $0.45^{* * *}$ & -0.08 & $0.12^{*}$ & 0.06 & $0.21^{* * *}$ & $0.11 *$ & -0.05 & 0.07 \\
\hline 3: Threat appraisal & & & 1.00 & $0.42^{* * *}$ & -0.03 & $0.11^{*}$ & $0.42^{* * *}$ & $-0.15^{* *}$ & 0.10 & -0.05 & $0.19^{* * *}$ & 0.07 & -0.04 & 0.07 \\
\hline 4: Worry & & & & 1.00 & $-0.14^{* *}$ & $0.15^{* *}$ & $0.36^{* * *}$ & $-0.29 * * *$ & -0.06 & -0.07 & $0.34^{* * *}$ & 0.08 & -0.02 & -0.05 \\
\hline 5: Perceived self-efficacy & & & & & 1.00 & -0.01 & 0.08 & 0.06 & -0.09 & $0.14^{* *}$ & 0.07 & -0.03 & 0.01 & 0.09 \\
\hline 6: Perceived efficacy of measures & & & & & & 1.00 & 0.08 & 0.07 & -0.05 & $0.22^{* * *}$ & $0.19^{* * *}$ & -0.03 & 0.05 & 0.07 \\
\hline 7: Threat experience appraisal & & & & & & & 1.00 & $-0.15^{* *}$ & -0.01 & $0.11 *$ & 0.06 & 0.06 & 0.05 & 0.02 \\
\hline 8: Reliance on public flood protection & & & & & & & & 1.00 & $0.13^{* *}$ & $0.16^{* *}$ & $-0.18^{* * *}$ & 0.03 & 0.02 & 0.07 \\
\hline 9: Education level & & & & & & & & & 1.00 & $0.21^{* * *}$ & 0.01 & $0.11 *$ & $-0.21 * * *$ & -0.05 \\
\hline 10: Department of residence & & & & & & & & & & 1.00 & -0.05 & 0.09 & $-0.15^{*}$ & -0.01 \\
\hline 11: Size of the municipality of residence & & & & & & & & & & & 1.00 & $-0.15^{* *}$ & -0.03 & -0.03 \\
\hline 12: Homeownership & & & & & & & & & & & & 1.00 & $0.32 * * *$ & 0.07 \\
\hline 13: Age & & & & & & & & & & & & & 1.00 & 0.05 \\
\hline 14: Gender & & & & & & & & & & & & & & 1.00 \\
\hline
\end{tabular}

$\mathrm{N}=272$. Significance levels: ${ }^{*} \mathrm{p}<0.1 ;{ }^{* *} \mathrm{p}<0.05 ;{ }^{* * *} \mathrm{p}<0.01$ 